
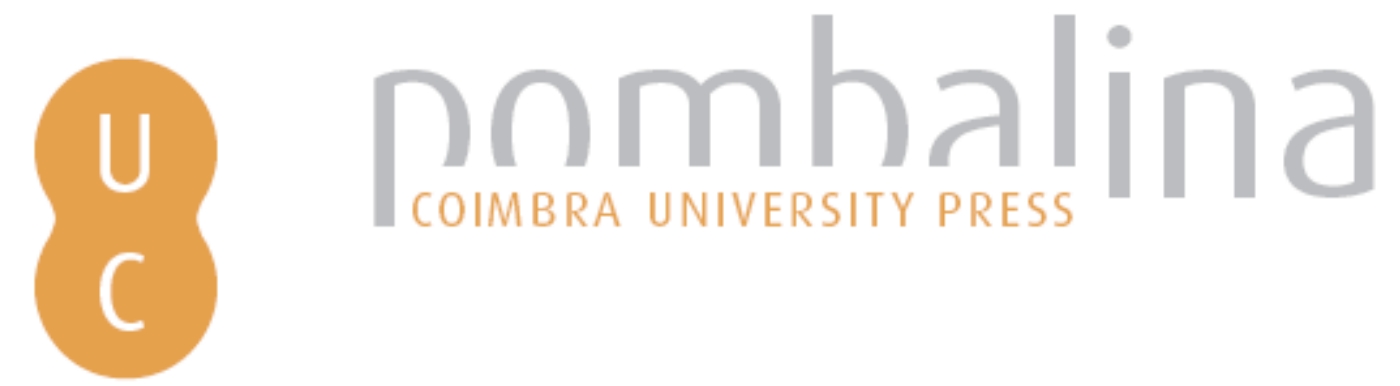

\title{
Norma e transgressão: contributos para a definição de padrões de identidade/alteridade nas Histórias de Heródoto
}

\author{
Autor(es): $\quad$ Soares, Carmen
}

Publicado por: Imprensa da Universidade de Coimbra

URL

persistente: URI:http://hdl.handle.net/10316.2/32110

DOI: $\quad$ DOI:http://dx.doi.org/10.14195/978-989-26-0368-1_2

Accessed : $\quad$ 26-Apr-2023 08:51:23

A navegação consulta e descarregamento dos títulos inseridos nas Bibliotecas Digitais UC Digitalis, UC Pombalina e UC Impactum, pressupõem a aceitação plena e sem reservas dos Termos e Condições de Uso destas Bibliotecas Digitais, disponíveis em https://digitalis.uc.pt/pt-pt/termos.

Conforme exposto nos referidos Termos e Condições de Uso, o descarregamento de títulos de acesso restrito requer uma licença válida de autorização devendo o utilizador aceder ao(s) documento(s) a partir de um endereço de IP da instituição detentora da supramencionada licença.

Ao utilizador é apenas permitido o descarregamento para uso pessoal, pelo que o emprego do(s) título(s) descarregado(s) para outro fim, designadamente comercial, carece de autorização do respetivo autor ou editor da obra.

Na medida em que todas as obras da UC Digitalis se encontram protegidas pelo Código do Direito de Autor e Direitos Conexos e demais legislação aplicável, toda a cópia, parcial ou total, deste documento, nos casos em que é legalmente admitida, deverá conter ou fazer-se acompanhar por este aviso.

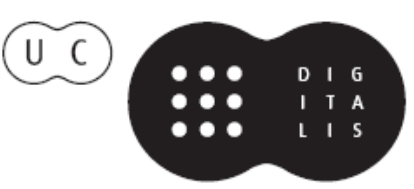


Carmen Soares

Inês Calero Secall

Maria do Céu Fialho

Coordenação

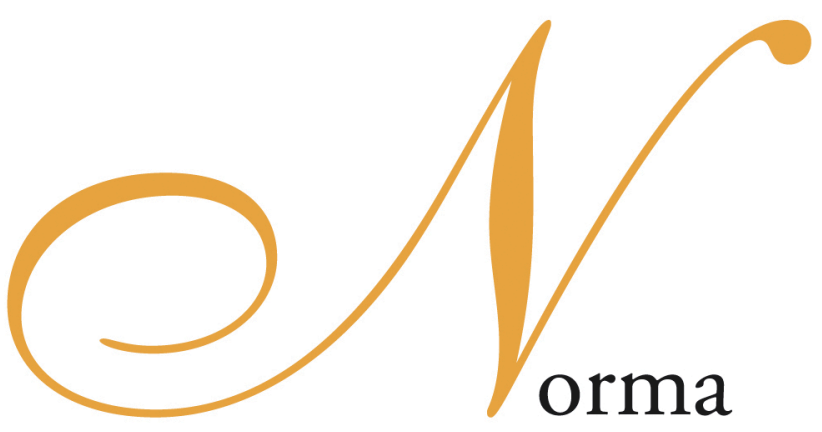

\& Transgressão 


\section{Carmen Soares}

Faculdade de Letras da Universidade de Coimbra

Centro de Estudos Clássicos e Humanísticos

\section{NORMA E TRANSGRESSÃO: CONTRIBUTOS PARA A DEFINIÇÃO \\ DE PADRÕES DE IDENTIDADE/ALTERIDADE NAS HistóRIAS dE HERÓdOTO”}

\section{Resumo}

As dinâmicas de construção da identidade ganham contornos particularmente propícios aos conflitos de identificação e tratamento em contexto de multiculturalismo. Na qualidade de entidade reguladora da vida em sociedade, a norma exerce sobre os indivíduos uma pressão institucional que pode resultar, por parte do 'eu' em relação a essa mesma norma, no desenvolvimento do sentimento de pertença ou despoletar uma atitude de fractura.

Determinante para o estabelecimento de contactos entre indivíduos de culturas diversas, a mobilidade tem, ao longo da história da humanidade, contribuído, se não para o desenho de identidades multiculturais, pelo menos para que o ego tome consciência de si, através do confronto com o alter. Neste estudo são considerados exemplos extraídos da obra do primeiro historiador, Heródoto, ilustrativos de como a juventude é uma fase da vida dos indivíduos tendencialmente favorável à ruptura, o mesmo é dizer, à transgressão da norma.

É hoje um lugar comum entre as reflexões produzidas no âmbito dos Estudos Culturais a ideia de que as sociedades contemporâneas são potencial-

* Este trabalho foi desenvolvido no âmbito do Projecto de Investigação da UI\&D-Centro de Estudos Clássicos e Humanísticos. 
mente multiculturais ${ }^{1}$. De facto, produto de uma longa prática de deslocação e contacto de pessoas, desde tempos ancestrais a história da humanidade tem-se desenhado sob o signo da mobilidade. Sempre que este fluxo origina a partilha de um mesmo espaço por parte de indivíduos com sistemas de esquemas de percepção, pensamento e acção diferentes ${ }^{2}$, ou seja, culturas diversas, verifica-se um de dois fenómenos. Ou temos a interacção, com troca/partilha de experiências, entre indivíduos de culturas distintas e estamos perante o que se pode designar por multiculturalismo de convivência. Ou, quando se verifica que pessoas de culturas diversas se limitam a partilhar apenas os mesmos espaços, mas fecham-se ao relacionamento intercultural, estamos perante o que entendo chamar multiculturalismo de coexistência, correspondente ao denominado multiculturalismo radical - estamos, neste caso, perante a doutrina do «juntos mas separados»3.

Todos conhecemos exemplos abundantes, tanto da história recente como da mais recuada, das consequências nefastas que para o relacionamento intercultural acarreta uma política de «desenvolvimento de culturas separadas e incontaminadas ${ }^{4}$. Basta pensar em manifestações e fenómenos de racismo e xenofobia, muitas vezes associados a fundamentalismos nacionalistas. Naturalmente, tanto as situações de diálogo, resultantes de uma interacção livre e solidária entre culturas, justamente conhecidas por mestiçagem em profundidade 5 , como as de fechamento deliberado à comunicação intercultural

\footnotetext{
${ }^{1}$ Particularmente relevante para as reflexões que irei fazer sobre a importância do diálogo/ confronto de culturas para a construção de identidades/alteridades é o estudo de E. Lamo de Espinosa, Culturas, estados, ciudadanos. Una aproximación al multiculturalismo en Europa (Madrid 1995) 13-79 (cap. "Fronteras culturales»).

${ }^{2}$ Definição de 'cultura', proposta por F. Javier Garcia Castaño (in «La educación multicultural y el concepto de cultura", in F. Javier García Castaño y Antolín Granados Martínez (edd.), Lecturas para educación (Madrid 1999) p. 73). Esta concepção não difere muito da que adopta E. Lamo de Espinosa, para quem 'cultura' significa: el conjunto de maneras de obrar, pensar o sentir específicas a um grupo bumano (op. cit., p. 15). Esta concepção, como esclarece (op. cit., p. 35), deriva da criada pelos pensadores alemães da chamada corrente romântico-historicista (desde Savigny a Herder).

${ }^{3}$ Cf. E. Lamo de Espinosa, op. cit., p. 18.

${ }^{4}$ Idem, ibidem.

${ }^{5}$ Sobre o conceito de mestiçagem e sua articulação com o de globalização, vd. J. M. André, "Globalização, mestiçagens e diálogo intercultural", Revista de História e Teoria das Ideias 25 (2004) 9-50.
} 
assentam sobre um mesmo processo de auto e hetero gnose: a consciência da identidade.

Um indivíduo ou um grupo apenas consegue definir a sua especificidade por confronto com algo que seja diferente ou outro. Em termos metafóricos, a imagem de uma pessoa a observar-se ao espelho é a que melhor serve para ilustrar a dinâmica da construção da identidade. O eu apercebe-se dos seus traços pela observação/constatação da sua imagem invertida. Como escreveu Emílio Lamo de Espinosa, es el otro quien me otorga/niega reconocimiento y es a través de su mirada como me formo un "yo". Yo solo lo soy para otro, y viceversa ${ }^{6}$. Longe vai a tentação essencialista, divulgada por pensadores alemães como Hegel, segundo a qual a cultura tem uma existência própria, autónoma e estanque. Segundo esta concepção, os indivíduos limitar-se-iam a aceitar a cultura na sua unicidade. A corrente interaccionista veio, já no séc. xx, defender precisamente que as culturas não existem per se, isto é, não são, mas que é da interacção de umas com as outras que elas se fazem $^{7}$. Dito de outra maneira: a experiência da identidade (do eu) nasce e consolida-se em correlação com a experiência da alteridade (do outro).

Porque, juntamente com F. Catroga, acredito que as sociedades contemporâneas não são amnésicas $^{8}$, importa ainda acrescentar que no processo de construção da identidade o outro assume também a forma de passado. Assim, num processo de construção da identidade, o indivíduo interage não só com a(s) sociedade(s) e grupo(s) em que se situa, mas também com a herança que a(s) mesma(s) lhe transmite(m). Esse diálogo produz-se de forma dinâmica; por um lado, o indivíduo estabelece com os valores e práticas vigentes relações que podem ser de solidariedade, adesão ou mesmo fractura; pelo outro, a sua relação com o património herdado pode ir da mera apropriação à reinterpretação. Daí que, em meu entender, seja um

\footnotetext{
${ }^{6}$ Op. cit., 29 sq.

${ }^{7}$ E. Lamo de Espinosa, op. cit., p. 17.

${ }^{8}$ As sociedades contemporâneas, na interpretação desse teorizador da história, estão, sim, a proceder a uma afirmação, ainda pouco perceptível, de novos ritos e novas formas de socializar e vivenciar memórias (in Memória, história e historiografia, Coimbra, 2001, p. 34).
} 
imperativo e necessidade da identidade própria de sujeitos ou grupos haver a re-presentificação e re-apresentação do passado. Porque narrar acontecimentos passados é trazê-los para o tempo da narração, recordar é sempre re-presentificar. Porque recordar é sempre seleccionar o passado, pois escolher implica excluir e silenciar, o que se narra não é o que aconteceu; estamos, pois, perante uma re-apresentação.

Consciente de que a história ou um património comum actua sobre os indivíduos como instrumentos de filiação indentitária, na qualidade de investigadora de Estudos Clássicos, proponho-me, uma vez mais, cumprir, através da presente reflexão, aquela que me parece ser a missão social das pessoas que investigam neste campo. Estou naturalmente a referir-me ao contributo que os nossos estudos devem dar para evitar a crise da memória nas sociedades contemporâneas. Combater a vivência do tempo como simples sucessão, na qual cada momento transporta o esquecimento do momento que o precedeu, é contribuir para ancorar o Homem de hoje numa história de cujo continuum faz parte e é obreiro principal.

Produto e produtor de cultura, o ser humano age, necessariamente, num contexto de hábitos, que se legitimam e reforçam ao formularem-se como normas ${ }^{9}$. Nesta minha abordagem, exemplificativa e não exaustiva, do contributo das Histórias de Heródoto para a construção da identidade/ alteridade através de percursos de transgressão à norma, ou seja, ao status quo, começarei por analisar a importância cimeira da regra (o nomos) tanto para Gregos como para não Gregos, os chamados Bárbaros. Não se verifica, no entanto, em nenhum desses contextos culturais, uma observância cega dos hábitos e valores institucionalizados.

\footnotetext{
${ }^{9}$ Cf. Lamo de Espinosa, op. cit., p. 15: «Para comenzar entenderé por cultura (en su sentido sociológico y antropológico) el conjunto de maneras de obrar, pensar o sentir específicas a un grupo humano. Se trata, pues, de repertorios de conducta, aparentemente regulada por repertorios de normas relativamente unificadas e integradas, y sustentadas por un conjunto jerárquico de valores que supuestamente legitiman y hacen compreensibles y razonables esas normas de conducta y las prácticas que a ellas responden. Lo importante de este esquema son las maneras de obrar, los hábitos, que se legitiman y refuerzan por referencia a creencias compartidas. Pero con frequencia esos mismos valores y creencias podrían dar lugar a otras normas distintas y esas mismas normas podrían dar lugar a otras conductas. De modo que, en última instancia, una cultura no es sino un conjunto de prácticas legitimadas y, por supuesto, institucionalizadas».
} 
De facto constata-se que, tal como sucede hoje, o grupo etário mais propenso a questionar e, muitas vezes, romper com as normas estabelecidas é o dos jovens. Do seu longo processo de formação e crescimento fazem parte, na qualidade de elementos estruturantes da identidade, manifestações de inconformismo. Por vezes as transgressões cometidas nesta fase da vida dos indivíduos configuram situações em que a motivação para infringir a norma (os actos de anomia) radica também na imponderação, resultante da inexperiência ou da inadequação aos valores institucionalizados.

Comecemos por considerar que as normas ocupam, na cosmovisão herodotiana, um papel estruturante do que poderíamos designar por identidade colectiva de um povo. As palavras que o historiador encontra para definir a identidade helénica, se interpretarmos o sentido de exclusão que encerram, desenham o perfil da alteridade. Ou seja, se a identidade

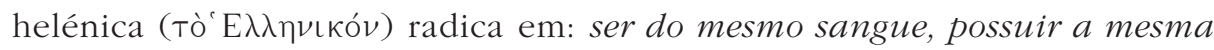
língua, os deuses e os ritos sagrados serem comuns, os costumes idênticos (8. 144, 2), aplicando o 'jogo de espelhos' que ajuda à construção do 'Eu', depreende-se que identidade não helénica, isto, a alteridade (o 'Outro'), consiste em não ser aquilo que é ser Grego. Como se percebe, os traços físicos e a cultura, constituem, na perspectiva do autor do séc. V a.C., os elementos caracterizadores da identidade helénica e não helénica. As

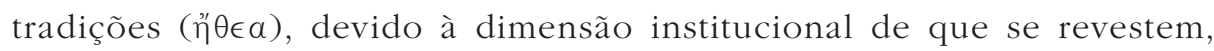
configuram-se como normas sociais, de importância soberana na formação da identidade individual e colectiva. O estatuto, reconhecido ao nomos, de referência contextualizante da identidade adquire, nas Histórias, o valor de princípio universal (i. e., comum a Gregos e Bárbaros). É o que se infere de três passos distintos da obra, que passo a considerar.

Referindo-se à aretê protagonizada pelos Gregos, Heródoto esclarece que, além do saber (sophia), tem sido um código rigoroso de normas (nomos ischyros) o factor responsável pela distinção do povo heleno ${ }^{10}$. Em suma, é

\footnotetext{
${ }^{10}$ Leia-se: "(..) para a Hélade a pobreza tem servido sempre de sustento; quanto ao mérito tem sido acrescentado através de um saber de experiência feito e de normas rigorosas. É desse (mérito) que a Grécia se serve para se defender da pobreza e da servidão. (...)» (7. 102. 1).
} 
na cultura que os enforma que os Helenos têm encontrado o estímulo para vencer a pobreza do solo pátrio e buscar a excelência. Particularizando sobre os Espartanos, Demarato, rei lacedemónio exilado na corte de Xerxes, faz o elogio dos soldados compatriotas destacando, precisamente, a relação de sujeição e obediência do indivíduo relativamente às normas da sociedade em que se insere. Dirigindo-se ao rei persa, o vassalo grego esclarece que:

Quando lutam individualmente, os Lacedemónios não são em nada inferiores aos outros, mas em grupo revelam-se os mais valentes guerreiros. Embora sejam livres, não o são em absoluto, pois têm por soberano um

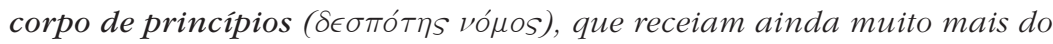
que os vossos súbditos a vós. Fazem o que a (lei soberana) dita; e a sua ordem é sempre esta: não abandonar o combate perante uma multidão de guerreiros, mas, permanecendo no seu posto, vencer ou morrer.

(7. 104. 4-5)

Todavia, para exprimir a pressão social exercida pelas normas sobre indivíduos de sociedades não gregas, Heródoto recorre a uma técnica discursiva diversa. De facto não tece uma afirmação explícita da "soberania» do nomos sobre os Bárbaros, mas refere-se-lhe indirectamente, isto é, verbaliza o sentimento de xenofobia, chegando, por vezes, a exemplificá-lo através de atitudes fundamentalistas. Dito de outra forma, é na recusa da abertura ao diálogo intercultural que povos como os Citas, nómadas das estepes situadas a norte do Mar Negro, e os Egípcios demonstram o peso que a tradição tem nas suas culturas.

O radicalismo da intolerância cita, conforme já tive ocasião de tratar noutro lugar, vem espelhado nas histórias de dois membros da família real ${ }^{11}$. A razão que ditou a execução de ambos foi a mesma, a saber: a transgressão de um código que determina a rejeição absoluta da adopção de práticas do 'outro'. É o que se depreende das seguintes palavras de Heródoto:

\footnotetext{
${ }^{11} \mathrm{Vd}$. "Tolerância e xenofobia ou a consciência de um universo multicultural nas Histórias de Heródoto", Humanitas 53 (2001) 49-82.
} 
Estes (os Citas) rejeitam de forma violenta a prática de costumes estrangeiros, próprios dos outros povos, e mais que todos os gregos, como tornaram evidente com os casos de Anacársis e, uma segunda vez, de Ciles.

(4. 76.1$)$

Sem assumir os contornos extremistas padronizados pelos Citas, também a actuação dos Egípcios vem expressamente referenciada por Heródoto em termos que deixam perceber o jugo exercido pela norma sobre os membros da respectiva sociedade:

Observadores das tradições dos antepassados, não lhes acrescentam outras.

Evitam adoptar os usos gregos e, para ser franco, os de todos os outros povos.

(2. 91. 1)

Feitas estas considerações sobre o valor normativo de hábitos e tradições no âmbito de diferentes culturas, importa considerar como, no processo de construção da identidade e da alteridade, há ocasiões várias para a ocorrência de conflitos de identificação e de tratamento. Na verdade, cada indivíduo associa à sua identidade determinado código de tratamento, por vezes não coincidente com o quadro construído pelo 'outro'. Desse desajuste entre as expectativas do ego e as atitudes do alter e vice-versa nascem conflitos culturais, responsáveis por dinâmicas distintas de lidar com a diferença.

Mais propensos à inflexão da norma, os jovens aparecem repetidas vezes nas Histórias no papel de protagonistas de conflitos de tratamento e identificação. Um dos episódios que, a meu ver, melhor ilustra um quadro tantas vezes encenado ao longo da história da humanidade, tem lugar no livro V (caps. 17-21). Aí deparamos com duas ordens de conflito. Por um lado assiste-se ao choque entre a norma macedónia (leia-se grega) e o costume persa em matéria de praxis do convívio; pelo outro temos o confronto entre o conformismo de um pai, amadurecido pela sageza adquirida 
ao longo dos anos, e a irreverência de um jovem filho, cuja inexperiência

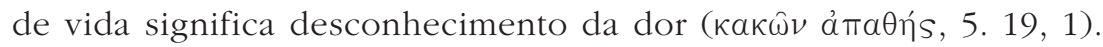

$\mathrm{Na}$ qualidade de senhores dos Macedónios, com quem Dario firmara uma aliança, os Persas esperavam que o anfitrião, o rei Amintas, os recebesse na sua corte segundo as regras sociais da Pérsia ${ }^{12}$. Significava isto que a expectativa de tratamento criada pelos Persas relativamente aos Macedónios era de que estes fizessem participar do festim de recepção não apenas as cortesãs, mas também as mulheres legítimas. Contudo a norma do anfitrião ditava, precisamente, a exclusão das últimas de um ambiente que poderia, sob o efeito do vinho, tornar-se propício ao contacto íntimo entre os convivas. Amintas não cede ao pedido dos hóspedes sem antes apresentar de viva voz qual era a norma do seu povo. No entanto, ao mesmo tempo que pactua com a transgressão, o soberano, submisso a um 'outro', aqui apresentado como invasor até do ponto de vista cultural ${ }^{13}$, está a verbalizar o conflito de tratamento subjacente ao diferendo protocolar. É o que se lê nas entrelinhas da resposta dada à demanda dos embaixadores persas:

"Persas, o costume que nós temos não é esse, mas sim o de separar os homens das mulheres. Mas visto que sois vós, na condição de senhores, que assim o exigis, ser-vos-á satisfeito esse pedido».

Introduzidas no convívio, as mulheres e filhas dos varões da Macedónia acabam por despertar nos hóspedes ébrios alguns gestos mais ousados (5. 18. 5). Inconformado com a cedência do pai, o príncipe Alexandre não só assume o lugar que este tinha no banquete como também desobedece

\footnotetext{
${ }^{12}$ Cf. 5. 18. 2, palavras de um embaixador persa: Anfitrião macedónio, nós os Persas temos por costume, quando oferecemos um grande festim, trazer para a nossa companhia tanto as cortesãs como as esposas legítimas. A ti, uma vez que nos recebeste de braços abertos, tratando-nos como hóspedes, e ofereces ao rei Dario terra e água, adopta agora a nossa tradição».

${ }^{13}$ De um modo geral a política cultural dos soberanos persas pautou-se pela tolerância, factor decisivo para a expansão territorial conseguida (cf. C. Duchesne-Guillemin, "Religion et politique de Cyrus à Xerxès", Persica 3, 1967-1968, 1-9; P. Briant, "Pouvoir central et polycentrisme culturel dans l' empire achéménide. Quelques réflexions et suggestions", in H. SancisiWeerdenburg, Achaemenid history I. Sources, structures and synthesis, Leiden 1987, 1-31).
} 
à sua vontade, isto é, corporiza um conflito de identificação e de tratamento. Ou seja, substitui o rei, mas não assume a atitude conciliadora que o caracterizava. Assim, não se tendo apercebido da mudança de tratamento implicada na substituição do anfitrião pelo filho, os Persas são surpreendidos pelo desenvolver dos acontecimentos. Esse erro de hetero-identificação por parte dos embaixadores persas relativamente a Alexandre e ao entourage feminino custar-lhes-á a própria vida.

O que se passa é que Alexandre contrariara deliberadamente o pedido do pai, de não alterar em nada o entendimento obtido com os hóspedes (5. 19. 2), atitude que materializa um 'conflito de gerações'. Quando substituiu, recorrendo ao travesti, as mulheres por jovens imberbes armados, enganou os Persas e condenou-os a um fim inesperado, a morte. Além disso, ao desobedecer ao pai, frustrando as expectativas de tratamento que o 'outro' (os Persas) tinha em relação ao 'eu' (o anfitrião macedónio), o príncipe, na interpretação de Amintas, tornava-se também responsável pela ruína da casa real. O desenrolar da história, no entanto, provou que o rei estava errado no seu juízo. Comprando o silêncio do chefe dos enviados para averiguar o desaparecimento dos Persas, Alexandre conseguiu evitar retaliações. Em suma, do processo de construção da identidade do 'eu' (Alexandre) faz parte o conflito com os 'outros' (o pai, Amintas, e os embaixadores Persas).

Ainda dentro deste motivo do jovem que sedimenta a construção da sua identidade na transgressão do nomos de que é herdeiro, incluem-se os casos dos supracitados Anacársis (4. 76-77) e Ciles (4. 78-80). Numa viagem de enriquecimento intelectual e formação por várias terras, o primeiro assiste, em Cízico, a uma festa em honra de Cíbele. Na ocasião exprime um voto à deusa: em retribuição de uma boa viagem de regresso, o Cita promete instituir-lhe na sua pátria uma vigília de homenagem. Porque tem consciência de estar a transgredir o nomos pátrio, que preconizava a rejeição absoluta de costumes estrangeiros, isto é, de estar a entrar em conflito com as expectativas de identificação que os Citas tinham dele, Anacársis procura um local recôndito para cumprir a promessa feita. 
O fim trágico reservado a esta personagem (o homicídio às mãos do próprio irmão), causado pela adopção de nomoi alheios, aproximam-na de Ciles. No entanto, a competência que cada um possui relativamente à cultura estrangeira adoptada permite distinguir claramente um indivíduo do outro. Comparando, pois, o grau de conhecimento que ambos têm da cultura do 'outro', verifica-se que a cultura grega contribui de forma bastante mais significativa para a construção da identidade multicultural de Ciles do que de Anacársis. Isto porque, enquanto este adoptou dos costumes estrangeiros apenas um aspecto definido da religião, aquele, várias vezes no ano e por períodos não inferiores a um mês, fala e vive à grega. Conforme esclarece o historiador, a dívida de Ciles para com a cultura grega tem uma explicação de ordem biológico-cultural. Filho de uma mãe de origem grega, natural de Ístria,

Apesar de exercer o poder sobre os Citas, Ciles não tinha o menor gosto

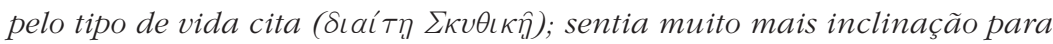
o modelo de vida grego ( desde criança. ${ }^{14}$

Assim, a relação do rei cita com a herança transmitida pela mãe é de reconhecimento. De facto, uma vez que a educação do indivíduo integra o património cultural grego, este actua na formação da identidade de Ciles como uma norma e uma dívida. Ou seja, são-lhe transmitidos valores e ritos, criadores de ordem/código/norma, em relação aos quais ele, enquanto herdeiro, nutre um sentimento de pertença. Os mecanismos que, no caso da personagem em apreço, propiciam o cimentar da filiação identitária com a cultura grega são os habituais nestes processos de inclusão: a repetição de rituais colectivos e a conservação de saberes e símbolos. No texto Heródoto refere expressamente alguns desses marcadores da identidade

\footnotetext{
${ }^{14}$ Tradução de M. Fátima Silva, in Heródoto. Histórias, livro $4^{\circ}$. Introdução, versão do grego e notas de Maria de Fátima Silva e Cristina Abranches Guerreiro (Lisboa 2000).
} 
(4. 78): o idioma (que Ciles aprende a falar e a escrever com a mãe), as vestes e algumas práticas religiosas (sacrifícios aos deuses e iniciação no culto mistérico de Dioniso).

Porque conhece bem a norma do povo cita, que exigia dos seus elementos um comportamento de total exclusão de qualquer tipo de mestiçagem cultural, o soberano toma precauções no sentido de evitar a revelação da sua filiação identitária multicultural. Pactuando com a política vulgarmente denominada pelo slogan do "todos juntos mas separados», Ciles entrega-se a um modo de vida alheio, debaixo da protecção das muralhas da colónia grega de Ólbia. Tem ainda o cuidado reforçado de manter sempre as portas da cidade sob vigilância, por forma a evitar ser visto por algum compatriota (4. 78. 4). A adesão à cultura grega é de tal forma estruturante da identidade do rei que ele desposa mesmo uma indígena e estabelece uma segunda residência no interior da cidade.

Mas a história de Ciles, à imagem da de Anacársis, configura um caso de conflito de identidade e tratamento entre o 'eu' e o 'outro'. Os súbditos de Ciles construíam do seu soberano uma identidade conforme aos padrões culturais citas, expectativa que vêem defraudada. Assim, a partir do momento em que descobrem a vida dupla do rei, passam a encará-lo como um 'outro', alteração que dá origem a um conflito de tratamento. À obediência substitui-se a sublevação e Ciles é mandado degolar pelo próprio irmão (4. 80). Extraindo da vida desta personagem uma evidência da pressão social da norma sobre os indivíduos, Heródoto conclui:

É deste teor o zelo dos Citas pelos seus costumes, e estes são os castigos que aplicam àqueles que neles introduzem práticas alheias.

Necessária à regularização da vida em sociedade, a norma estabelece com o seu produtor e produto, o indivíduo, uma relação de conformidade e/ou fractura. A análise que levei a cabo neste estudo permite confirmar a ideia de que os conflitos do 'eu' com as regras estabelecidas, as próprias e as do 'outro', tiveram, têm e, muito possivelmente, continuarão a ter um 
papel determinante na construção de percursos de identidade/alteridade de cada sujeito ou grupo, isto é, na configuração do tecido multicultural das 40 sociedades de todos os tempos. 